\title{
Effects of Aqueous Leaf Extract of Velvet Bean (Mucuna Pruriens) on Reproductive Outcome in Adult Female Wistar Rats
}

\author{
*EJEGUO, A; ORHERUATA, RA; SAKPA, CL
}

\author{
Department of Anatomy, School of Basic Medical Sciences, College of Medicine, University of Benin, Benin City, Edo State, Nigeria \\ *Corresponding Author Email: akporobo.ejeguo@uniben.edu
}

\begin{abstract}
From ancient times in many parts of the world, herbal medications have been used for the treatment of various ailments. Mucuna pruriens is a leguminous plant that has various medicinal purposes. Literature reports state that it enhances normal fertility, healthy sperm and ova, proper functioning of the reproductive organs and appropriate genital secretions. This present study was done to study the effects of the aqueous leaf extract of M. pruriens on reproductive outcome in adult female Wistar rats. Twenty-four adult Wistar rats were used for this research. These animals were randomly divided into four groups of six (6) rats each. The animals were weighed before commencement and during the period of the experiment. All animals received water and feed ad libitum. Group A served as control. Groups B and C received $500 \mathrm{mg}$ and $1500 \mathrm{mg} / \mathrm{kg}$ bodyweight of extract respectively for 10days before mating. Group D comprised of the male animals used for mating the females. After littering, the pups were counted and weighed. The statistical apparatus used for analyzing the data was IBM/SPSS version 20 and the method employed was ANOVA. Results were taken to be statistically significant when $\mathrm{P}<0.05$. Group $\mathrm{B}$ showed no significant increase $(\mathrm{P}>0.05)$ in bodyweight change of dams as well as in pup weight. Group $\mathrm{C}$ on the other hand showed a significant increase $(\mathrm{P}<0.05)$ both in the bodyweight change of dams but not in pup weight. A dose dependent increase in reproductive outcome and pregnancy success rate was observed in animals of group B and C. Findings from this study indicate that Mucuna pruriens has pro-fertility potential. It is therefore safe to administer extract in experimental animals to enhance their reproductive ability.
\end{abstract}

DOI: https://dx.doi.org/10.4314/jasem.v23i5.33

Copyright: Copyright $\odot 2019$ Abdul et al. This is an open access article distributed under the Creative Commons Attribution License (CCL), which permits unrestricted use, distribution, and reproduction in any medium, provided the original work is properly cited.

Dates: Received: 10 April 2019; Revised: 16 May 2019; Accepted 21 May 2019

Keyword: Mucuna pruriens, reproductive outcome, fertility, litter size

Human use of plants date back from fossil records to the middle Paleolithic age, some 60,000 years ago. From that time, plants have been included as a means of therapy in traditional medical systems (Solecki, 1975). According to the World Health Organisation (WHO), about $65 \%$ of the world has included plants in their primary modality of health care. Due to high biodiversity and endemism, the tropical forest is generally considered to be the most likely habitat to discover new pharmaceuticals (Ayensu et al., 1978). According to WHO, the prevalence of usage of medicinal plant remedies is higher in developing countries, with about $65 \%-80 \%$ of the populations using such products (WHO, 2011). It might be expected that plants bioactive compounds would have low toxicity to man. However, some plants may have acute or chronic toxic effects when used (Farnsworth and Daniel, 2001).

Amongst medicinal plants, Mucuna pruriens (L) is an important specie that was first discovered about 4500 years ago in India for the treatment of Parkinson's disease. The plant has lots of alkaloids that have actions on the nervous system (Sastry and Kavathekar, 1990; Agharkar, 1991; Singh et al., 1996). The plant became popular in the international market with the discovery of the presence of L-DOPA (L3,4dihydroxyl phenyl alanine) which is an antiParkinson's drug in the seeds (Farooqi, 1999).

Mucuna pruriens (MP) belongs to the family of Leguminosae and it has up to 100 species. MP is found in the woodlands of tropical areas especially in Africa, Asia, India and the Caribbean. The hairs on the plant cause itchiness and this is as a result of the presence of mucunain and serotonin (Agharkar, 1991). In Nigeria, the common name is "devil's bean" and its medicinal use is widely prevalent (Ezueh, 1977; Infante et al., 1990; Osei-Bonsu et al., 1995).

On phytochemical analysis, the seeds of MP contain high concentrations of L-DOPA. Other constituents include gluthathione, lecithin, gallic acid, beta sitosterol, nicotine, dimethyl tryptamine. The leaves also contain $0.5 \%$ L-DOPA (Erowid, 2002). The plant is used against a wide range of conditions which include neurological, menstrual disorders, urinary tract problems, fever, ulcers and constipation. It is also useful as a hypoglycemic, vermifuge, anti- 
hypertensive and carminative agent (Katzenschlager et al., 2004). In addition, it is prevalently useful as an aphrodisiac. The powdered sample of the seeds was also found to increase mating and sexual activity in rats (Amin et al., 1996).

Infertility is regarded as one of the most important reproductive health concern of men and women across the globe (Okonofua, 2003; Megafu, 1988). WHO in 2013 defined infertility as "a disease of the reproductive system defined by the failure to achieve a clinical pregnancy after 12 months or more of regular unprotected sexual intercourse". Worldwide, about $3 \%-7 \%$ of all couple have unresolved fertility problem (Himmel et al., 1997). The occurrence of infertility varies from region to region around the world, being highest in Africa. The incidence is about $10-15 \%$ in developed countries and about $20-46 \%$ in developing countries (Idrisa et al., 2005; Alvarez, 2006). The use of herbs in the treatment of infertility as well as other diseases is attributed to the high cost of synthetic drugs, previous notion that herbal medicines are safe and also due to the belief that there is an unscientific cause to such diseases (Fido, 2004; Canter and Ernst, 2004; Qato et al., 2008; Loya et al, 2009; Cohen and Ernst, 2010).

Among fertility herbs used in Nigeria, $M$. pruriens is popularly recommended because it is said to be one of the best reproductive tonics for both men and women. The plant enhances normal fertility, healthy sperm and ova, proper functioning of the reproductive organs as well as appropriate genital secretions (Agbafor and Nwachukwu, 2011). A significant dose dependent increase in follicle stimulating hormone (FSH), progesterone and luteinizing hormone $(\mathrm{LH})$ levels for both male and female rats have been reported (Obasi et al., 2016). The methanolic seed extract slightly raised superoxide dismutase levels in female Spraguedawley rats and caused a dose dependant increase in the levels of FSH and LH levels with increase in oocyte number (Noah et al., 2014).

The objectives of this study was to investigate the effects of aqueous leaf extract of Mucuna pruriens on pregnancy success rate and reproductive outcome on adult female Wistar rats.

\section{MATERIALS AND METHOD}

This research was conducted with the aid of the following materials; Cages, Gloves, Scale, Dissecting set, Plastic specimen bottles, Knife, Embedding mould, Spatula, Disinfectant, Calibrated Syringes, Micropipette, Cotton wool, Refrigerator, Light microscope, Rotary microtome, Laboratory coat, Slides, Orogastric tube, Pencil, Slide rack, Weighing balance, Oven, Water bath, Electric weighing balance, Hand gloves, $10 \%$ formal saline, Hematoxylin, Eosin, Ethanol, Xylene, Paraffin wax, Normal saline.

Animals: Twenty four (24) adult Wistar rats with mean weight of $220 \mathrm{~g}$ were bred in the Department of Anatomy University of Benin and maintained under standard condition for the use of laboratory animals (National institute of Health Guide for the use and Care of Laboratory Animals). During this period, the animals were fed with Growers' mash, manufactured by Premier Feed Mills Co. Ltd (a subsidiary of Flour Mills of Nigeria Plc.) and water ad libitum.

All animals were maintained at room temperature with approximate light/dark cycle of 12:12 hours. The animals were randomly divided into four groups of six (6) animals each.

Group A was the control and the animals received feed and $1 \mathrm{ml}$ of distilled water daily to compensate for stress of administration incurred in the treated groups.

Groups $B$ and $C$ were administered 500mg and $1500 \mathrm{mg} / \mathrm{kg}$ body weight of the extract respectively for 10days before mating.

Group $D$ was the male animals of same standard of proven fecundity used to mate the females.

All administration was done through oral route with the aid of an orogastric tube. The animals were weighed weekly throughout the period of the experiment.

Data Analysis: Data obtained was tested for significant variance between the values obtained from the test groups and the control. The significant difference in the mean values of all parameters was determined using one-way analysis of variance $(95 \%$ confidence interval). Post-hoc test was also carried out for all the groups. All statistical analysis was carried out using Statistical Package for Social Sciences (SPSS), version 20, manufactured by International Business Machine Corporation (IBM) in Armonk, New York.

\section{RESULTS AND DISCUSSION}

Change in Body weight: The change between the initial and final body weight of dams in the showed no significant increase $(\mathrm{P}>0.055)$ for rats treated with $500 \mathrm{mg} / \mathrm{kg}$ body weight (group B1) of MP for 10days before mating when compared to control. There was however significant increase $(\mathrm{P}<0.002)$ between rats treated with $1500 \mathrm{mg} / \mathrm{kg}$ body weight (group B2) when compared with the control. 
Pregnancy Success Rate: The pregnancy success rate for the control was $83.3 \%$, the low dose had $100 \%$ while the high dose also had a success rate of $83.3 \%$. Litter Size: There was no significant difference ( $\mathrm{P}>0.467)$ when the litter size was compared between the low dose and control. However, there was a significant $(\mathrm{P}<0.010)$ increase in the litter size when comparing the high dose and the control.

Pup Weight: Comparing the birth weight of the pups, it was observed that there was no significant increase $(\mathrm{P}>0.121 ; \mathrm{P}>0.06)$ when the low and high dose was compared with the control.

Table 1. Weight and litter size

\begin{tabular}{|c|c|c|c|}
\hline Parameters & Control & Treated Groups & \\
\hline \multirow[t]{2}{*}{ Weight Change (g) } & $(39.50 \pm 1.00)$ & Low Dose $(48.25 \pm 5.44)$ & 0.055 \\
\hline & $(39.50 \pm 1.00)$ & High Dose $(56.00 \pm 8.00)$ & 0.002 \\
\hline \multirow[t]{2}{*}{ Litter Size } & $(7.00 \pm 1.00)$ & Low Dose $(7.75 \pm 1.50)$ & 0.467 \\
\hline & $(7.00 \pm 1.00)$ & High Dose $(10.67 \pm 1.15)$ & $0.010 *$ \\
\hline \multirow[t]{2}{*}{ Pup Weight (g) } & $(5.92 \pm 0.19)$ & Low Dose $(5.75 \pm 0.29)$ & 0.121 \\
\hline & $(5.92 \pm 0.19)$ & High Dose $(6.17 \pm 0.50)$ & 0.060 \\
\hline
\end{tabular}

Values are represented as Mean \pm SEM for each group; $n=6 /$ group; *indicates significant difference $(P<0.05)$ compared to control.

The herb under investigation in this study has been used in many cultures across the world for its revitalizing and fertility enhancing effects. Pregnancy success rate was same in control and high dose $(83.3 \%)$ whereas the low dose had a $100 \%$ success rate. Thus the low dose is more efficient in fertility purpose. The reproductive outcome with the use of $M$. pruriens was markedly increased. Considering the litter size, a dose dependent increase was observed as the higher dose produced an average of 10 pups while the low dose produced 8 pups, in contrast with the control that had an average of 6 pups. The increase in the number of oocytes released at ovulation with the use of MP has also been reported in previous report by using the seed (Noah et al., 2014). It can be attributed to the presence of L-Dopa in the leave (Misra and Wagner ,2006). Increase in dopamine, a metabolite of L-Dopa has been reported to stimulate gonadotrophin releasing hormone $(\mathrm{GnRH})$, which in turn activates the secretion of follicle stimulating hormone (FSH), resulting in the increase in oocyte number. This increase in oocyte number is thus evident as the corresponding increase in the reproductive outcome as seen in this study. It can therefore be said that the use of $M$. pruriens increases fertility and can be used as a potent medication in females. However, since the pregnancy success rate is higher for the low dose than the high dose, it is assumed that the high dose that greatly increased the reproductive outcome does not have a corresponding aphrodisiac effect.

It was also shown that $M$. pruriens caused a dose dependent increase in weight in treated animals. This increased bodyweight is possibly due to the higher litter size observed in the treatment groups when compared with the control. The pups also did not show significant increase in the birth weight when the treatment groups were compared with control. The use of some other herbs such as Echinacea has also been documented to have insignificant effect on infant birth weight and gestational age in a retrospective study in Canada (Gallo et al., 2000).

Conclusion: From the results of this study, it is clearly seen that $M$. pruriens is safe at various doses and the occurrence of over dose is almost infinitesimal. Also, the report of its pro-fertility effect has been reaffirmed and it is recommended that the low dose has an overall beneficial effect than the high dose.

\section{REFERENCES}

Agbafor, KN; Nwachukwu, N (2011). Phytochemical analysis and antioxidant property of leaf extracts of Vitex doniana and Mucuna pruriens. Biochem Res Inter Article id 459839

Agharkar, SP (1991). Medicinal Plants of Bombay Presidency. Scientific Publication, Jodhpur, India Pp1-2

Alvarex, NC (2006). Infertility; The Magnitude of this Problem. Rev Enferm 29: 59-62

Amin, KMY; Khan, MN; Rahman, HSZ (1996). Sexual Function Improving Effect of Mucuna Pruriens in Sexually Normal Male Rats. Fitoterapia 67(1): 5358

Ayensu, ES; De Filipps. RA (1978). Endangered and Threatened Plants of the United States. Washington DC: Smithsonian Institution

Canter, PH; Ernst, E (2004). Herbal Supplements Use by Persons Aged over 50years in Britain. Frequently Used Herbs, Concomitant Use of Herbs, Nutritional Supplements and Prescription Drugs; Rate of Informing Doctors and Potential for Negative Interactions. Drugs Aging 21: 597-605 
Cohen, PA; Ernst, E (2010). Safety of Herbal Drugs Supplements; A Guide for Cardiologists. Cardiovasc Ther 28: 240-253

Erowid (2002). Mucuna Pruriens. Created 2002-APR22. International Legume database and Information Service. Genus Mucuna. Version 10.01

Ezueh, MI (1977). Cultivation and Utilization of Minor Food Legumes in Nigeria. Tropical Grain Legume Bulletin 10

Farnsworth, NS; Daniel, SF (2001). The Value of Plant Used in Traditional Medicine for Drug Discovery. Environ Health Perspect 109 (suppl 1): 69-75

Farooqi, AA; Khan, MM; Asundhara, M (1999). Production Technology of Medicinal and Aromatic Crops. Natural Remedies Pvt. Ltd., Bangalore, India. Pp 26-28

Fido, A (2004). Emotional Distress in Infertile Womwn in Kuwait. Int. J. Fertil. Women's Med 49:24-28

Gallo, M; Sarkar, M; Au, W (2000). Pregnancy Outcome Following Gestational Exposure to Echinacea: a Prospective Controlled Study. Archives of Internal Medicine 160:3141-3143

Himmel, W; Ittner, E; Kochen, MM; Michelmann, HW; Himmey, B; Reuter, M; Katterhoff, M; Ringer, RH (1997). Voluntary Childlessness and Being child Free. British Journal of General Practice 47 (415): 111-118

Idrisa, A (2005). Infertility: Comprehensive Gynaecology in the Tropics. Accra Graphics Packaging pp 333-343

Infante, ME; Perz, AM; Simao, MR; Manda, F; Baquete, EF; Fernabdes, AM; Cliff GL (1990). Outbreak of Acute Toxic Psychois Attributed to Mucuna pruriens. The Lancet 336: 1129

Katzenschlager, R; Evans, A; Manson, A (2004). Mucuna pruriens in Parkinson disease; a Double Blind Clinical and Pharmacological Study. $J$. Neurol. Neurosurg. Psychiatry 75:1672-1677

Loya, AM; Gonzalez-Stuart, A; Rivera, JO (2009). Prevalence of Polypharmacy, Polyherbacy, Nutritional Supplement Use and Potential Product
Interactions Among Older Adults Living in the United States-Mexico Border; A Descriptive Questionnaire-Based Study. Drugs Aging 26: 423436

Megafu, U (1988). Surgical Causes and Management of Infertility in Nigeria. Int. Surg. 73: 144-148

Misra, L; Wagner, H (2006). Lipid Derivatives from Mucuna pruriens seeds. Ind J Chem 45(3):801-804

Noah, OT; Gbotolorun, SC; Oremosy, AA (2014). Fertility Enhancing Potential of Mucuna pruriens Seeds in Female Sprague-dawley Rats. Bri J Medi Med Res 4(16):3148-3157

Obasi, NA; Obasi, SE; Otuchristian, G; Nvene, C; Akalonu, XC (2016). Effects of Oral Administration of Ethanolic Leaf Extract of Mucuna pruriens Obtained from Afikpo on Serum Liver Biomarkers and Sex Hormones in Albino Wistar Rats. Int Res $J$ Nat App Sci 3(7):2349

Okonofua, FE (2003). Infertility in Sub-Saharan Africa, Contemporary Obstetrics and Gynaecology for Developing Countries. Women's Health and Action Research Center, Benin City pp 128-156

Osei Bonsu, P; Buckles, D; Soza, F R; Asibuo, JY (1995). Traditional Food Uses of Mucuna Pruriens and Canavalia ensiformis in Ghana. ILEIA Newslater 12 (2): $30-31$

Qato, DM; Alexander, GC; Conti, RM; Johnson, M; Schumm, P; Linau, ST (2008). Use of Prescription and Over the Counter Medications and Dietary Supplemnets Among Older Adults in the United States. JAMA 300: 2867-2878

Sastry, CST; Kavathekar, YY (1990). Plants for Reclamation of Wastelands. Publications and Information Directorate. New Delhi Pp317-318

Singh, U; Wadhwani, AM; Johri, BM (1996). Dictionary of Economic Plants in India. Indian Council of Agriculture research, New Dehli Pp 45-46

Solecki, RS IV (1975). A Neanderthal Flower Burial in Northern Iraq. Science 190: 880-881

WHO; World Health Organisation (2011). The World Traditional Medicines Situation in Traditional Medicines 